\title{
Design of Voice Coil Type Linear Actuator for Hydraulic Servo Valve Operation
}

\author{
Baek Ju Sung \\ Korea Institute of Machinery\&Materials, Daejeon, Korea
}

Email address:

sbj682@kimm.re.kr (Baek Ju Sung)

To cite this article:

Baek Ju Sung. Design of Voice Coil Type Linear Actuator for Hydraulic Servo Valve Operation. American Journal of Electrical Power and Energy Systems. Special Issue: Electrical Special Machines. Vol. 4, No. 5-1, 2015, pp. 1-8. doi: 10.11648/j.epes.s.2015040501.11

\begin{abstract}
In this study, we proposed governing equations for voice coil type linear actuator for valve operation. We draw up governing equations which are composed by combination of electromagnetic theories and empirical knowledge, and deduct the values of major design factors by use of them. We suggested the governing equations to determine the values of design parameters of linear actuator as like bobbin size, length of yoke and plunger and turn number of coil. And we also calculated the life test time of linear actuator for verification of reliability of the prototype. In addition, for reducing the life test time, the acceleration model of linear actuator is proposed and the acceleration factor is calculated considering the field operating conditions. Finally we have proven the propriety of the governing equations by accelerated life test using the valve assembly adopted the voice coil type linear actuator prototype.
\end{abstract}

Keywords: Linear Actuator, Permanent Magnet, Governing Equation, Design Factor, Voice Coil Type, Accelerated Model, Life Test, Frequency Response Test

\section{Introduction}

The linear actuator is a very economical motion converter due to its simple structure as electromagnetic energy converting to kinetic energy. And the linear actuator is used as key components in automobile and aircraft industry. For having higher response time and product reliability, two kinds of different techniques are needed. One is the optimal design method for linear actuator. A regarded point for design of linear actuator is flux density analysis, determination of plunger shape and mass, optimal bobbin design, selected magnetic analysis, determination of duty ratio, and calculation of coil turn number which is regarded temperature rising. For the optimal design of the linear actuator, theoretical and empirical knowledge are simultaneously needed. Theoretical knowledge governs the operational characteristics of the linear actuator, and empirical knowledge compensates for the theoretical limitation obtained from the designer's design and manufacturing experiences for various kinds of linear actuator [1]. They cannot be determined solely by calculation or simulation because the empirical knowledge is more essential than theoretical knowledge for determination of the plunger shape and value of the space factor. When designer's accumulated experiences and expertise are added to these, the most proper shape and value of them can then be obtained.

In this study, the governing equations for design of linear actuator were derived by a combination of electromagnetic knowledge and empirical knowledge. And also the no-failure test time of voice coil type linear actuator is calculated. In particular, for reducing of the no-failure test time, the acceleration model of linear actuator is proposed, and the acceleration factor is calculated with the reality. The validity of the proposed design method and deducted reliability parameters are proved by accelerated life test and performance test

\section{Governing Equations}

\subsection{Structure of High Speed Linear Actuator}

Fig. 1 shows the structure of high speed linear actuator for valve operation. It is composed of an excitation coil for generation of magnetic field, yoke for flux path, plunger for creation of mechanical stroke, stationary for attraction of the plunger, bearing for guidance of movement, and centering springs [2]. 


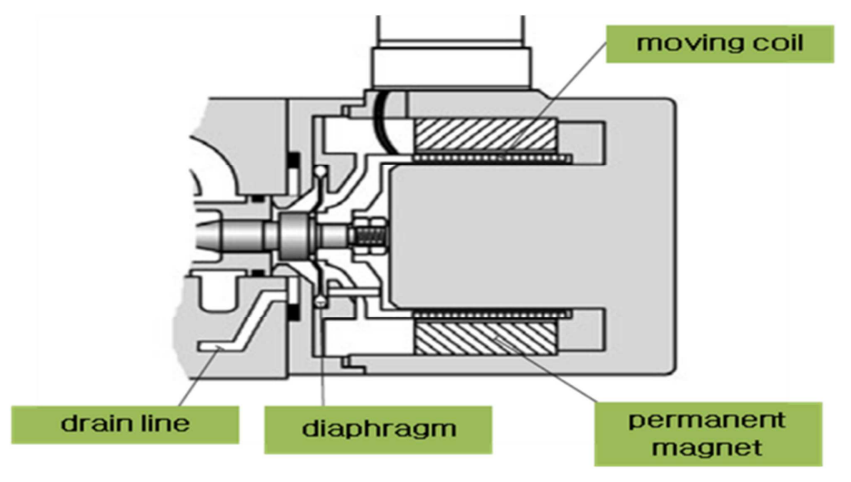

Figure 1. Structure of linear actuator.

Fig. 2 represents the simplified structure of high speed linear actuator, where the permanent magnets are excluded. Permanent magnet independently compensates the electromagnetic force of solenoid coil, and it contributes the reduction of consumption power and increasing of operational speed in comparison with the case of only used solenoid coil.

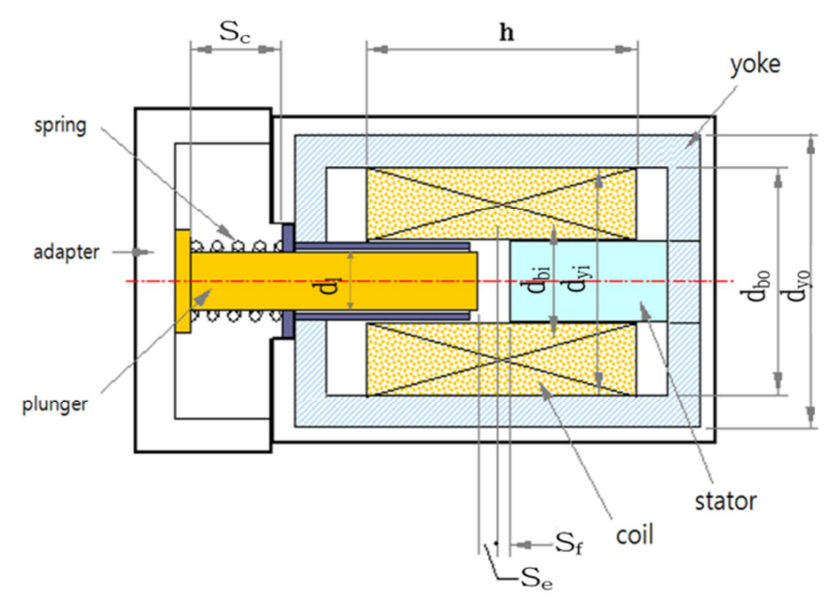

Figure 2. Simple structure of linear actuator

\subsection{Magnetic Flux Density and Magnetic Motive Force in Air Gap}

The attraction force $F$ is shown in equation (1) in the magnetic circuit of Fig. 2 [1] [3] [8].

$$
F=\frac{B^{2} \bullet S}{2 \mu_{0}}[N]
$$

Where $S$ is cross sectional area of plunger, as it were, it is $\pi\left(\frac{d_{l}}{2}\right)^{2}$ when $d_{l}$ is radius of plunger, and $\mu_{0}$ is permeability in the air.

Therefore from equation (1), the magnetic flux density $B$ needed in air gap is expressed as equation (2).

$$
B=\sqrt{\frac{F \bullet 2 \mu_{0}}{S}}
$$

And theoretical magneto motive force $U_{m}$ are shown in equation (3) and, $d$ is maximum distance between plunger and stationary.

$$
U_{m}=\frac{B \bullet d}{\mu_{0}}
$$

Equation (4) is obtained from equations (1) and (3), and also, the design coefficient $K_{f}$ can be expressed as equation (5).

$$
\begin{aligned}
& F=\frac{K_{f}}{d^{2}} \\
& K_{f}=\frac{\mu_{0} \bullet S \bullet U_{m}^{2}}{2}
\end{aligned}
$$

When the length of fixed air gap is $S_{f}$ in Fig.2, the maximum distance $d$ between plunger and stationary is given to equation (6) that is represented by the sum of fixed air gap $S_{f}$ and plunger stroke. So, the maximum attraction force $F_{\max }$ and the minimum attraction force $F_{\min }$ become equations (7) and (8), respectively.

$$
\begin{gathered}
d=S_{f}+S_{e} \\
F_{\max }=\frac{K_{f}}{S_{f}^{2}} \\
F_{\text {min }}=\frac{K_{f}}{d^{2}}
\end{gathered}
$$

\subsection{Permanent Magnet and Flux Density in Air Gap}

By reference [5-6], the total magnetic flux density in the air gap generated as equation (9) [5-6].

$$
B_{g}=\frac{B_{r} \bullet h_{M}}{\frac{A_{g}}{A_{m}} h_{M}+\mu_{M} S_{f}}
$$

And the permeability of permanent magnet $\mu_{M}$ is like equation (10).

$$
\mu_{M}=\frac{B_{r}}{H_{c} \mu_{0}}
$$

From equation (9), we can know that the magnetic flux density of air gap approaches to the residual magnetic flux density when the length of permanent magnet is long and the length of air gap is completely short.

For decision of operating point of permanent magnet, we must consider the maximum energy area of permanent magnet and the reduced magnetic flux due to reaction of magnetic 
field by solenoid coil. But, in this paper, the change of characteristic of permanent magnet may not be occurred because the operating point of permanent magnet resulted from completely short length of air gap and path of magnetic flux.

\subsection{Estimation of Yoke Thickness}

Referring Fig.2, inner diameter $d_{y i}$ and outer diameter $d_{y o}$ of yoke are as equation (11) and (12).

$$
\begin{gathered}
d_{y i}=d_{b o}+C_{g} \\
d_{y o}=\sqrt{d_{y i}^{2}+C_{p} \bullet d_{l}^{2}} \\
\text { Yoke thickness }=\left(d_{y o}-d_{y i}\right) / 2
\end{gathered}
$$

The empirical constant $C_{g}$ in equation (11) is the length margin for smooth heat dissipation of the coil, and the empirical constant $C_{p}$ in equation (12) is the length margin for smooth passing of magnetic flux [7] [9-10]. The proper values of the experience coefficients can be decided by designer's judgment depend on his experience and electromagnetic knowledge.

\subsection{Temperature Rising and Bobbin Length}

Heat dissipation coefficient $\lambda$ is the amount of heat energy radiated form the coil surface. It can be founded in Fig. 3 [1].

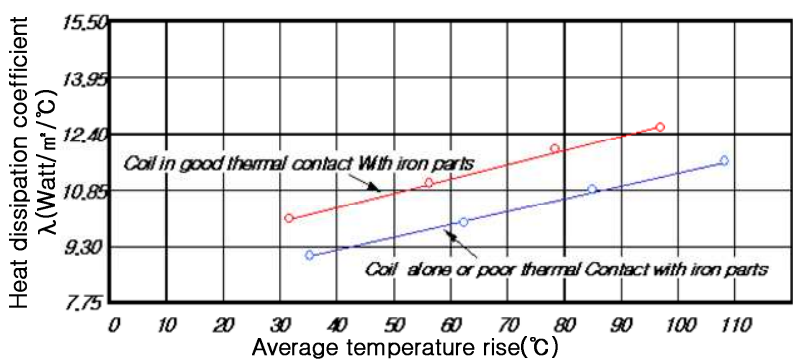

Figure 3. Heat dissipation coefficient according to temperature rising [1].

$R$ and $I$ passing through it produce the $T_{f}$ in equation (14). By substituting equations (15) and (16) into equation (14), we can make the constructive equation of final temperature rising as equation (17). Equation (14) is usually used temperature rising equation in the coil [1].

$$
\begin{aligned}
& T_{f}=\frac{W}{2 \bullet \lambda \bullet S}=\frac{I^{2} \bullet R}{2 \bullet \lambda \bullet S} \\
& R=\rho \frac{\left(l_{m} \bullet N^{2}\right)}{h \bullet w \bullet X_{i}} \\
& X_{i}=\frac{\pi}{4}\left(\frac{d_{s}}{d_{0}}\right)^{2}
\end{aligned}
$$

$$
T_{f}=\frac{q \bullet \rho}{d \bullet \lambda \bullet X_{i} \bullet w} \bullet\left(\frac{N \bullet W}{h \bullet V}\right)^{2}
$$

Where $S$ is area of heat dissipation.

Bobbin length (coil height) used in equation (15) is calculated by equation (18).

$$
h=\sqrt[3]{\frac{\left(q \bullet \beta \bullet \rho \bullet U^{2}\right)}{2 \bullet \lambda \bullet X_{i} \bullet T_{f}}}
$$

That is, $\beta$ is equal to $\frac{h}{w}$ referring to Fig.5, which is shown in the detailed drawing of the bobbin and yoke in Fig. 1 [7].

\subsection{Number of Turns and Consumption Power Coil}

Mean length of coil $l_{m}$ turn is represented as equation (19).

$$
l_{m}=\frac{\pi\left(d_{b o}+d_{b i}\right)}{2}
$$

And the relation between equivalent resistance $R_{t}$ of solenoid circuit using copper wire, supply voltage $V$, current $I$, and relative resistance $\rho$ and be expressed by equation (20).

$$
R_{t}=\frac{V}{I}=4 \rho\left[\frac{\left(l_{m} \bullet N\right)}{\pi \bullet d_{s}^{2}}\right]
$$

Diameter of bare wire, $d_{s}$ is induced to equation (21) from equation (20).

$$
d_{s}=\sqrt{\left(\frac{2 \bullet \rho \bullet\left(d_{b o}+d_{b i}\right) \bullet U}{V}\right)}
$$

If it is assumed that insulated wire diameter is $d_{0}$ and the winding loss of a winding layer is 1 turn, the total turns number to be winded $n_{c}$ in shaft direction given in equation (22). And, the total layer number $m_{c}$ of coil in the radial direction is given by equation (23).

$$
\begin{aligned}
& n_{c}=\left(\frac{h}{d_{0}}\right)-1 \\
& m_{c}=\frac{w}{d_{0}}
\end{aligned}
$$

Therefore the total turn number $N$ to be winded on the bobbin can be given by equation (24).

$$
N=n_{c} \bullet m_{c}
$$


By combining equations (20) and (21), the equivalent resistance $R_{t}$, which represents the total resistance of coil, is fully obtained by equation (25).

$$
R_{t}=\frac{2 \bullet \rho \bullet\left(d_{b o}+d_{b i}\right) \bullet N}{\pi d_{s}^{2}}
$$

According to determination of $R_{t}$, the equations of coil current $I$ and consumption power $W$ are determined by equations (26) and (27), respectively.

$$
\begin{array}{r}
I=\frac{V}{R_{t}} \\
W=V \bullet I
\end{array}
$$

\subsection{Operating Frequency}

The solenoid actuator can be expressed as return spring -mass system like Fig. 4. After applying power, plunger displacement is equivalent to the displacement of mass $\mathrm{mp}$ [8].

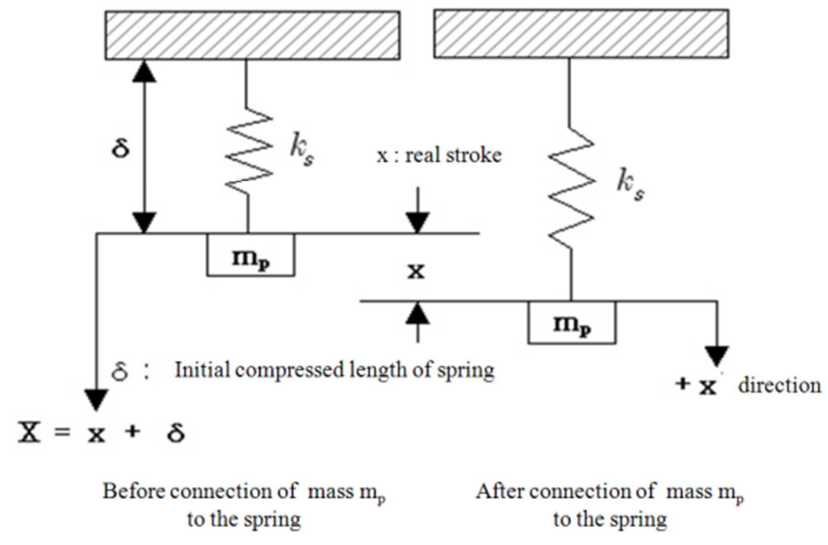

Figure 4. Mechanical model of solenoid actuator.

The state equation of mass $m_{p}$ to the $\mathrm{x}$-direction is equation (28). By substitution of $X=x+\delta$ to equation (28), we can achieve equation (29).

$$
\begin{aligned}
& m_{p} \ddot{X}+k_{s} X=m_{p} g \\
& m_{p} \ddot{x}+k_{s} x=0
\end{aligned}
$$

Therefore, mathematical model about the system of Fig. 4 become to equation (34).

$$
\ddot{x}+\omega^{2} x=0
$$

Here, the operating speed $\omega$ and operating frequency $f_{p}$ of the actuator can be expressed by equation (31) and (32), respectively [8].

$$
\begin{gathered}
\omega=\sqrt{\frac{K_{s}}{m_{p}}} \\
f_{p}=\frac{\omega}{2 \pi}
\end{gathered}
$$

\section{Design Program}

The target specifications of prototype actuator for the hydraulic valve are as shown in Table 1 .

Table 1. Material properties of SCP10.

\begin{tabular}{ll}
\hline Items & Target performance \\
\hline Supply voltage & $24 \mathrm{~V}$ \\
Consumption power & $55 \mathrm{~W}$ \\
Operating frequency & $100 \mathrm{~Hz}$ \\
Attraction force & $160 \mathrm{~N}$ \\
\hline
\end{tabular}

Fig. 5 shows the flow chart of the developed design program which is programmed by use of the governing equations and empirical coefficients in Chapter 2.

Designer's judgment means designer's experience which is needed to judge the fact whether the final design parameters are proper for manufacturing of target actuator or not.

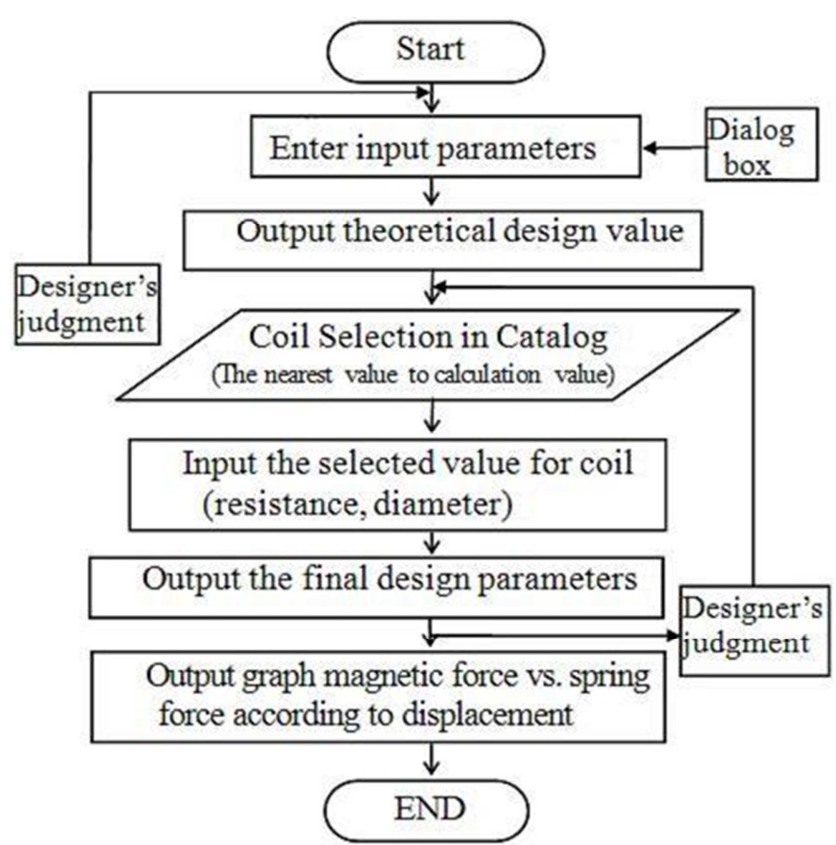

Figure 5. Flow chart of design program.

The input parameters and their values needed for design of the prototype are introduced in Table 2. 
Table 2. Input parameter.

\begin{tabular}{ll}
\hline Items & Input value \\
\hline$F_{\min }[\mathrm{N}]$ & 160 \\
$d_{l[\mathrm{~mm}]}$ & 4 \\
$t_{b}[\mathrm{~mm}]$ & 1 \\
$n_{c}$ & 59 \\
$m_{c}$ & 8 \\
$C_{g}$ & 0.004 \\
$C_{p}$ & 1.25 \\
$V \quad[\mathrm{~V}]$ & 24 \\
$\mathrm{mp}[\mathrm{g}]$ & 9.4 \\
$\mathrm{Ks}[\mathrm{kgf} / \mathrm{mm}]$ & 4.5 \\
\hline
\end{tabular}

\begin{tabular}{|c|c|}
\hline \multicolumn{2}{|c|}{ important output variable } \\
\hline \multicolumn{2}{|l|}{ Attraction force [N] } \\
\hline $\mathrm{F}_{\min }$ & 160 \\
\hline \multicolumn{2}{|c|}{ Magnetic flux density [T] } \\
\hline$B=2^{*}\left[\operatorname{root}\left(2^{*} \mu_{0}{ }^{*} \mathrm{~F}_{\min }\right) /\left(\mathrm{d}_{1}{ }^{*} \operatorname{root}(\pi)\right)\right.$ & 2.334 \\
\hline \multicolumn{2}{|c|}{ bobbin inner diameter $[\mathrm{mm}]$} \\
\hline $\mathrm{d}_{\mathrm{bi}}=\mathrm{d}_{1}+2\left(\mathrm{r}_{\mathrm{air}}+\mathrm{t}_{\mathrm{b}}\right)$ & 38 \\
\hline \multicolumn{2}{|c|}{ bobbin outer diameter [mm] } \\
\hline$d_{b o}=d_{b i}+2 w$ & 50 \\
\hline \multicolumn{2}{|c|}{ turn number of coil [No] } \\
\hline $\mathrm{N}=\mathrm{n}_{\mathrm{c}}{ }^{*} \mathrm{~m}_{\mathrm{c}}$ & 502.775 \\
\hline \multicolumn{2}{|c|}{ yoke inner diameter $[\mathrm{mm}]$} \\
\hline $\mathrm{d}_{\mathrm{yi}}=\mathrm{d}_{\mathrm{bo}}+\mathrm{C}_{\mathrm{g}}$ & 50.004 \\
\hline \multicolumn{2}{|c|}{ yoke outer diameter [mm] } \\
\hline $\mathrm{d}_{\mathrm{yo}}=\operatorname{root}\left(\mathrm{d}_{\mathrm{yi}}{ }^{2}+\mathrm{C}_{\mathrm{p}}{ }^{*} \mathrm{~d}_{1}{ }^{2}\right)$ & 54.17 \\
\hline \multicolumn{2}{|l|}{ equivalent resistance $[\Omega]$} \\
\hline$R_{t}=\left(2^{*} \rho^{*}\left(d_{b o}+d_{b i}\right)^{*} N\right) / d_{s}^{2}$ & 10.95 \\
\hline \multicolumn{2}{|l|}{ coil current $[\mathrm{A}]$} \\
\hline $\mathrm{I}=\mathrm{V} / \mathrm{R}_{\mathrm{t}}$ & 2.19178082 \\
\hline \multicolumn{2}{|c|}{ magnetic motive force (at $\left.20^{\circ} \mathrm{C}\right)[\mathrm{A} \cdot \mathrm{T}]$} \\
\hline $\mathrm{U}_{20}=\mathrm{I}^{\star} \mathrm{N}$ & 1101.9726 \\
\hline \multicolumn{2}{|c|}{ consumption power (at $\left.20^{\circ} \mathrm{C}\right)[\mathrm{W}]$} \\
\hline $\mathrm{W}_{20}=\mathrm{V}^{*} \mathrm{I}$ & 52.6027397 \\
\hline \multicolumn{2}{|c|}{ operating frequency $[\mathrm{Hz}]$} \\
\hline$f_{p}=\omega / 2 \pi$ & 110 \\
\hline
\end{tabular}

Figure 6. Result of design.
By input of the values in Table 2 to the design program, we can obtain the results of Fig.6 as a numerical output.

\section{Manufacturing of Prototype}

The prototype is manufactured by based on the design results and FEM analysis in previous chapters. Solenoid in made by plastic bobbin and copper coil, plunger is made by processing core steel, and yoke tube is installed for offering the smooth magnetic flux path between these. And, the permanent magnets are installed in front and rear of plunger for more increasing the operating speed.

For preventing the sticking of plunger onto the core tube, non-magnetic bushings of which thickness is $0.3 \sim 0.5 \mathrm{t}$ is inserted in front and rear of the core tube. The permanent magnets must put together to be confronted the same magnetic poles, at here, we put together the $\mathrm{S}$ poles are to be confronted by base of plunger. And, two pieces of centering springs are installed for security of neutral position of plunger in both side permanent magnets.

In addition, solenoid bearing is inserted in front of core tube. This plays a role to minimize the friction force and make the plunger locate in spatial center of inner core tube. Push rod is unified with plunger by laser welding after pressing, the rod bar transfers the attraction force of plunger to spool.

The components of manufacturing prototype shows in Fig.7, and the assembly is also shows in Fig.8.

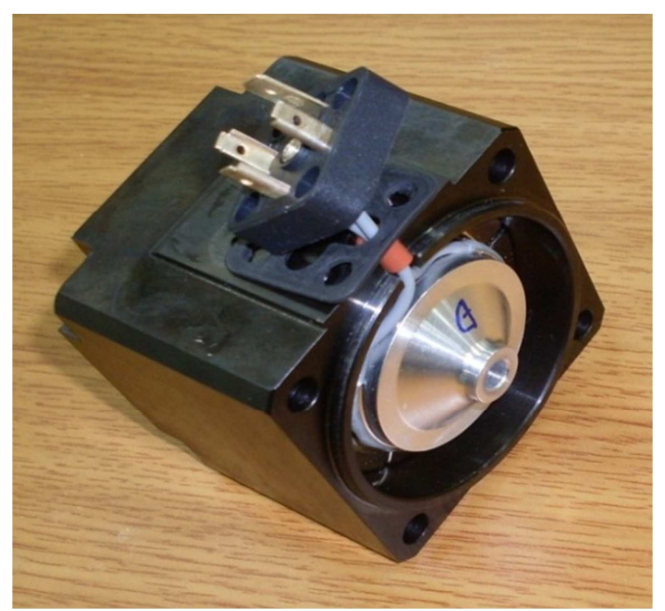

Figure 7. Prototype of voice coil type actuator.

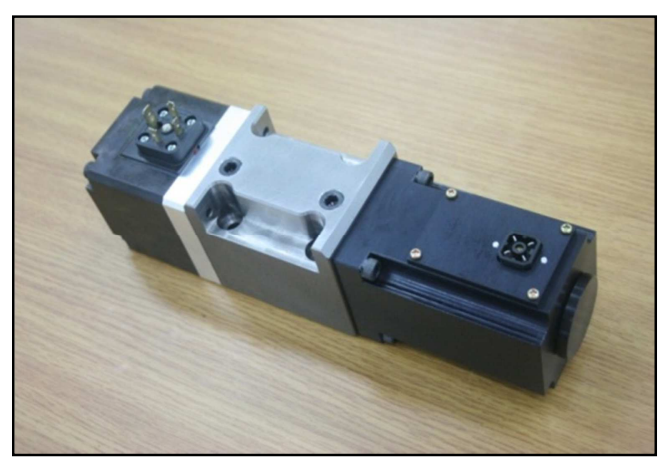

Figure 8. Hydraulic valve assembly. 


\section{Acceleration Model of Linear Actuator}

Domestic industries surveyed integral servo valve operating conditions the lifetime of the field by considering the $90 \%$ confidence level $B_{10}$ life of $1.0 * 10^{7}$ cycles that were guaranteed. According to the survey of the literature, shape parameter of 1.1 Weibull distributions follows. Reliability standards for the evaluation of servo valve in the prescribed lifetime of $1.0 * 10^{7}$ cycles $\left(\mathrm{B}_{10}\right.$ life) means to guarantee the following.

-Lifetime distribution : Shape parameter( $\beta$ ) 1.1

Weibull distribution[10]

- Insurance life : $1.0 * 10^{7}$ cycles $\left(B_{10}\right.$ Lifetime)

- Confidence level : $90 \%$

- Prototype : 3 ea

At this point, no-failure test time was calculated equation (37) using, the result is $6.1 * 10^{7}$ cycles.

$$
\begin{gathered}
t_{n}=B_{100 p} \bullet\left[\frac{\ln (1-C L)}{n \bullet \ln (1-p)}\right]^{\frac{1}{\beta}} \\
t_{n}=1.0 \times 10^{7} \bullet\left[\frac{\ln (1-0.9)}{3 \bullet \ln (1-0.1)}\right]^{\frac{1}{1.1}} \cong 1.0 \times 10^{7} \text { cycles }
\end{gathered}
$$

Where,

$t_{n}:$ No failure test time

$B_{100 p}:$ Assurance life

$C L$ : Confidence level

$n:$ Number of prototype

$p$ : Unreliability (if $B_{10}, p=0.1$ )

$\beta$ : Shape parameter

However, because no-failure test time is too long to accelerate the model chosen, and accelerated life test of time should be calculated. Failure modes related to the pressure and flow of the servo valve. Pressure and flow are chosen to acceleration stress. Considering the pressure and flow General Log-Linear acceleration model applied to the test conditions. So the acceleration factor is calculated acceleration time fault-tolerance test. 7.0 $\mathrm{MPa}, 50 \mathrm{~L} / \mathrm{min}$ and acceleration, conditions $25.2 \mathrm{MPa}, 88 \mathrm{~L} / \mathrm{min}$ was chosen as the acceleration factor calculation Thus, equation (38) 22.8096 .

$$
\begin{gathered}
A F=\left(\frac{P_{\text {test }}}{P_{\text {field }}}\right)^{m} \times\left(\frac{F_{\text {test }}}{F_{\text {field }}}\right)^{l} \\
=\left(\frac{25.2}{7.0}\right)^{2} \times\left(\frac{88}{50}\right)^{1}=22.8096
\end{gathered}
$$

Where,

$A F:$ Acceleration Factor

$P_{\text {test }} P_{\text {field }}:$ Acceleration \& field pressure (MPa) $\omega_{\text {test }} \quad \omega_{\text {field }}$ : Acceleration \& field flow (L/min)

$m, l$ : Acceleration index $(m=2, l=1)$

Calculated acceleration factor equation (39) by substituting the acceleration test, time $\left(t_{n a}\right)$ is produced.

$$
t_{n a}=\frac{t_{n}}{A F}=\frac{61,000,000}{22.8096} \cong 2.7 \times 10^{6} \text { cycles }
$$

\section{Life Test and Performance Tests}

\subsection{Accelerated Life Test}

The propriety of the design equations has been proven equations through the accelerated life test. the 3 units the valve assembly adopted the linear actuator are used to life test. Fig. 9 shows the accelerated life test.
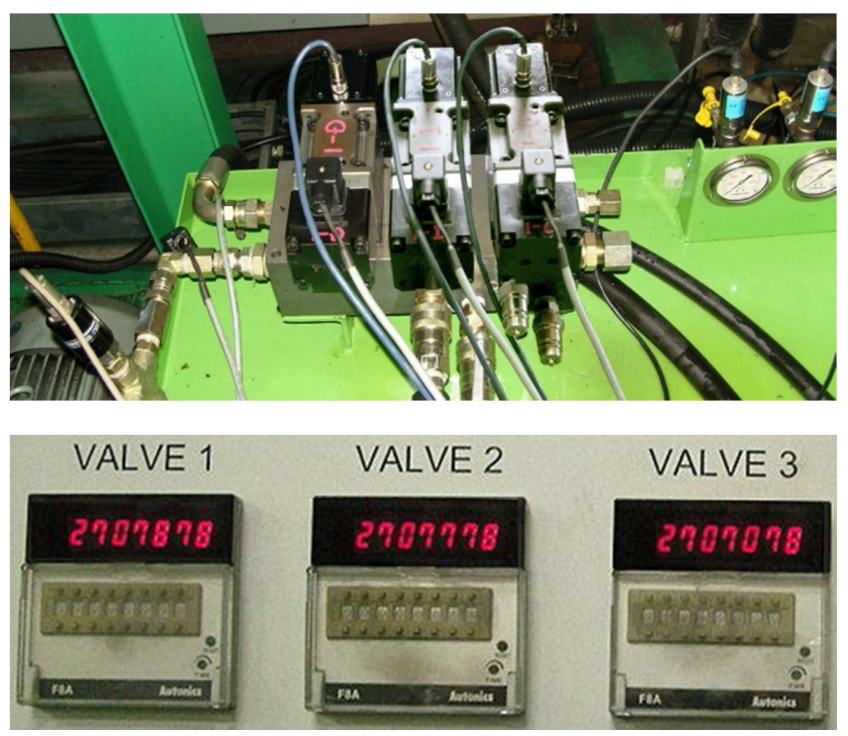

Figure 9. Accelerated life test.

\subsection{Attraction Force and Linearity Test}

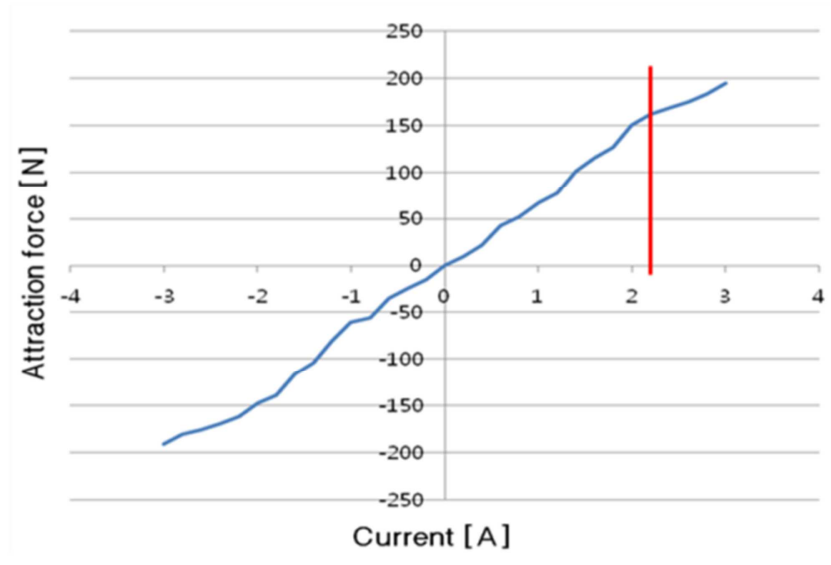

Figure 10. Result of attraction force test.

For attraction test, firstly, the prototype linear actuator is to be fastened on the attraction force test equipment, and it is connected to load cell by mechanical coupling. The attraction 
force should be measured changing the value of current form 0 to $+3 \mathrm{~A}$ and form 0 to $-3 \mathrm{~A}$. Fig. 10 represents the measuring result of the attraction force. From Fig. 10, the attraction force is about $153 \mathrm{~N}$ at rated current $\pm 2.2 \mathrm{~A}$. And, the linearity is almost approaching to the first order function, $\mathrm{f}(\mathrm{x})=3.5 \mathrm{x}$. At this time, for overall region, the error rate of linearity is $1.90 \%$, and the error rate of symmetrical characteristic is $3.05 \sim-2.00 \%$. These mean that the test results for attraction force and linearity are generally satisfactory to the target performance in the table 1 .

\subsection{Test of Step Response}

This test is to measure the time difference between supplying time of input step signal and reaction time of plunger. At here, the $100 \%$ control signal $(10 \mathrm{~V})$ to controller is used as input step signal, and reaction of plunger is detected by output signal of LVDT. Referring to fig. 11, the step response time is $3.8 \mathrm{~ms}$.

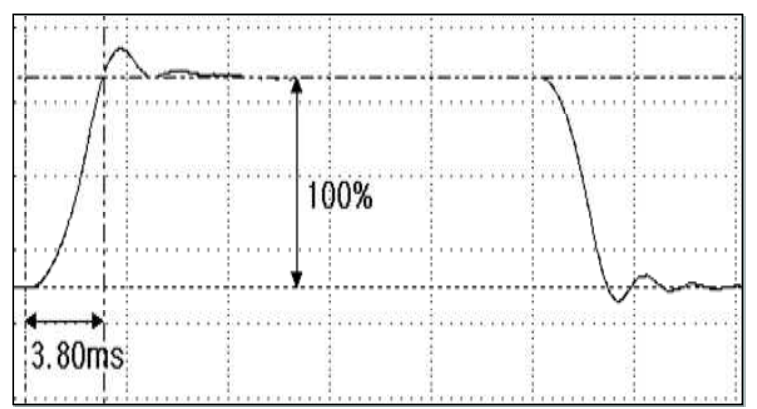

Figure 11. Result of step response test.

\subsection{Test of Frequency Response Test}

This test is similar to the test of step response. The input is control signal of controller and output is reaction signal of LVDT. This test performed at $25 \%$ magnitude of input signal with $0.01 \mathrm{~Hz} \sim 500 \mathrm{~Hz}$ carrier frequency region.

Fig. 12 is the test results for $25 \%$ control signal of controller. It shows that the $-3 \mathrm{~dB}$ frequency is about $187 \mathrm{~Hz}$ in gain and $330 \mathrm{~Hz}$ in phase.

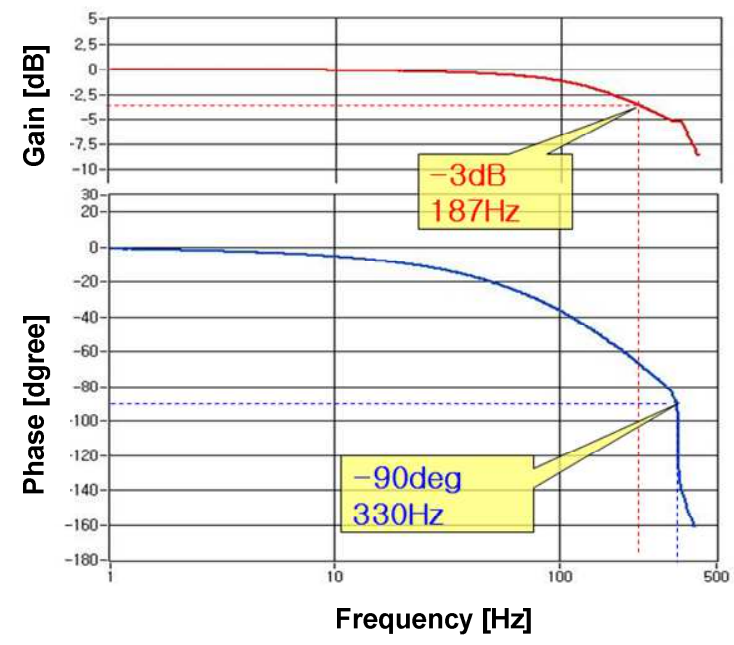

Figure 12. Result of frequency response test.

\section{Conclusion}

In this paper, all design courses of voice coil type high speed actuator for valve operation have been introduced. The final results are as follows:

1) The governing equations are induced for design using between electromagnetic theories and empirical knowledge. The important values of the design factors are decided as the results of optimal design through the governing equations.

2) For experiments, a prototype of the voice coil type actuator using the above design results was manufactured. As results of experiments, the attraction force test is less than target performance. But the frequency response test is better than target performance. It's difference is $230 \mathrm{~Hz}$. The important performance as linear actuator is high speed response for the signal.

3) These test results mean that the performance of the prototype linear actuator was satisfactory for the specifications of general high speed actuator for valve operation, and the induced governing equations are propriety for optimal design of voice coil type high speed actuator for valve operation.

\section{Nomenclature}

$A_{g}$

$A_{m}$

$B$

$B_{g}$

$B_{r}$

$C_{g}$

$C_{m}$

$C_{p}$

$d$

$d_{b o}$

$d_{b i}$

$d_{l}$

$d_{o}$

$d_{s}$

$d_{y i}$

$d_{y o}$

F

$F_{\text {max }}$

$F_{\text {min }}$

$f_{p}$

$h$ cross sectional area of air gap

pole area of permanent magnet

magnetic flux density

total magnetic flux density in the air gap

residual magnetic

empirical constant 1

empirical compensation coefficient

empirical constant 2

maximum distance between plunger and stationary

outer diameter of bobbin

inner diameter of bobbin

radius of plunger

diameter of insulated coil

diameter of bare wire

inner diameter of yoke

outer diameter of yoke

attraction force

maximum attraction force

minimum attraction force

operating frequency

coil height 


$\begin{array}{ll}h_{M} & \text { length of permanent magnet } \\ I & \text { current } \\ K_{f} & \text { design coefficient } \\ k_{s} & \text { spring constant } \\ l_{m} & \text { coil mean length per single turn } \\ m_{c} & \text { total layer number } \\ m_{p} & \text { mass } \\ N & \text { total turn numbers } \\ n_{c} & \text { total turn number to be winded } \\ q & \text { duty ratio } \\ R & \text { resistance } \\ R_{t} & \text { equivalent resistance } \\ S & \text { cross sectional area of plunger } \\ S_{e} & \text { plunger stroke } \\ S_{f} & \text { length of fixed air gap } \\ T_{f} & \text { rising temperature } \\ U & \text { actual magneto motive force } \\ U_{m} & \text { theoretical magneto motive force } \\ V & \text { supply voltage } \\ W & \text { consumption power } \\ W_{3} & \text { coil layer thickness } \\ \delta & \text { ratio of bobbin height } \\ \lambda & \text { initial compressed length of spring } \\ \mu_{0} & \text { heat dissipation coefficient } \\ \mu_{M} & \text { permeability in the air } \\ & \text { permeability of permanent magnet } \\ & \\ S^{\prime} & \end{array}$

$\rho \quad$ relative resistance

\section{References}

[1] C. Roters, "Electro Magnetic Device", John Wiley \& Sons, Inc, 1970.

[2] B. J. Sung, E. W, Lee, H. E. Kim, "Development of Design Program for On and Off Type Solenoid Actuator: Proceedings of the KIEE Summer Annual Conference 2002(B), pp929 931, 2002.7.10.

[3] William H. Hayt, "Engineering Electromagnetics", Mc Grawhill, 1986.

[4] T. Kajima, "Dynamic Model of the Plunger Type Solenoid at deenergizing State", IEEE Transactions on Magnetics, Vol.31, No.3, pp2315 2323, May 1995.

[5] Syed A. Nasar, I. Boldea "Solenoid Electric Motors" Prentice-Hall Inc englewood Cliffs, New Jersey 1987.

[6] H.-D. Stolting, A. Beisse, "Elektrische Kleinmaschinen”, B. G. Teubner Stuttgart, 1987.

[7] Hydraulic and Pneumatic Lap of KIMM, "Development of low Consumption Power Type Solenoid Valve", KIMM-CSI annual report, 2001.12.

[8] K. Ogata, "System Dynamics”, Prentice Hall, 1998.1.

[9] B. J. Sung, E. W. Lee, H. E. Kim, "Characteristics of Non-magnetic Ring for High-Speed Solenoid Actuator", The eleventh Biennial IEEE Conference on Electromagnetic Field Computation, pp342, Korea, June 2004.

[10] Kanda Kunio, "Design Concept for DC Solenoid of Pneumatic Valve", KIMM research reporter, 1997. 